\title{
From electronic navigational chart data to sea-bottom models: Kriging approaches for the Bay of Pozzuoli
}

\author{
Emanuele Alcaras ${ }^{1}$, Claudio Parente ${ }^{2}$, Andrea Vallario ${ }^{2}$ \\ ${ }^{1}$ International PhD Programme "Environment, Resources and Sustainable Development", Department of Science and Technology, \\ Parthenope University of Naples, Centro Direzionale, Isola C4, (80143) Naples, Italy \\ ${ }^{2}$ DIST - Department of Science and Technology, Parthenope University of Naples, Centro Direzionale, Isola C4, (80143) Naples, Italy
}

\begin{abstract}
Electronic Navigational Charts (ENCS), official databases created by a national hydrographic office and included in Electronic Chart Display and Information System (ECDIS), supply, among essential indications for safe navigation, data about sea-bottom morphology in terms of depth points and isolines. Those data are very useful to build bathymetric 3D models: applying interpolation methods, it is possible to produce a continuous representation of the seafloor for supporting studies concerning different aspects of a marine area, such as directions and intensity of currents, sensitivity of habitats and species, etc. Many interpolation methods are available in literature for bathymetric data modelling: among them kriging ones are extremely performing, but require deep analysis to define input parameters, i.e. semi-variogram models. This paper aims to analyze kriging approaches for depth data concerning the Bay of Pozzuoli. The attention is focused on the role of semi-variogram models for Ordinary and Universal kriging. Depth data included in two ENCs, namely IT400129 and IT400130, are processed using Geostatistical Analyst, an extension of ArcGIS 10.3.1 (ESRI). The results testify the relevance of the choice of the mathematical functions of the semi-variogram: Stable Model supplies, for this case study, the best performance in terms of depth accuracy for both Ordinary and Universal kriging.
\end{abstract}

Section: RESEARCH PAPER

Keywords: ENC Data; 3D Modelling; ordinary and universal Kriging interpolation; bathymetry; geospatial analysis

Citation: Emanuele Alcaras, Claudio Parente, Andrea Vallario, From electronic navigational chart data to sea-bottom models: Kriging approaches for the Bay of Pozzuoli, Acta IMEKO, vol. 10, no. 4, article 9, December 2021, identifier: IMEKO-ACTA-10 (2021)-04-09

Section Editor: Silvio Del Pizzo, University of Naples 'Parhenope', Italy

Received March 8, 2021; In final form December 10, 2021; Published December 2021

Copyright: This is an open-access article distributed under the terms of the Creative Commons Attribution 3.0 License, which permits unrestricted use, distribution, and reproduction in any medium, provided the original author and source are credited.

Corresponding author: Emanuele Alcaras, e-mail: emanuele.alcaras@uniparthenope.it

\section{INTRODUCTION}

The knowledge of the seabed conformation allows not only safe navigation [1], but also the development of new frontiers for other kind of studies such as those on directions and intensity of currents [2], sensitivity of habitats and species [3], [4], and other activities such as maintenance dredging [5], coastal infrastructure protection [6] etc. It is therefore obvious that knowing the seabed and its variability is a fundamental requirement in marine studies.

The Hydrographic Institute of the Italian Navy (Istituto Idrografico della Marina Militare - IIMM) represents the primary public authority in the study and analysis of the sea depths surrounding the Italian peninsula [7]. It is, in fact, the only institution that can produce certified cartography for navigation in Italy.

The IIMM conduces hydrographic surveys that permit to acquire water depth measurements. Hydrographic survey can be carried out by using different techniques. Single beam sonar (SBS) and multi beam sonar (MBS) determine the depth of any waterbody by using sound beams. Particularly, they measure the time lag between transmitting and receiving a signal that travels through the water, springs back the seafloor, and returns to the sounder; the time lag is converted into a range using the known speed of sound [8]. SBS is a less expansive system that MBS but provides much lower spatial resolution [9]. A good level of information about seabed morphology can be extract by multispectral satellite images, even if only in shallow water (depths less than 20 meters) [10], [11].

The results of bathymetric survey are used for nautical charts that provide seabed morphology through depth points and contours [12]. Available in digital form (raster or vector), nautical charts are legible and manageable by information systems supporting ship navigation, i.e. Electronic Charting Systems (ECSs) and Electronic Chart Display and Information Systems (ECDISs) [13]. When they are in vector format and comply 
specific standard established by the International Hydrographic Organization (IHO), digital nautical charts are named Electronic Navigational Charts (ENCs). ECDIS and ENC are the two fundamental components of the electronic navigation: the first performs the functions of the hardware, the second supplies the relevant information for a voyage, including bathymetry in form of depth points and contour lines.

Regardless of the technique with which they are obtained and the source from which they are extracted, data concerning seabed morphology can be used to produce bathymetric model that, according to $\mathrm{IHO}$, can be defined, as "a digital representation of the topography (bathymetry) of the seafloor by coordinates and depths" [14].

When a point cloud dataset is available, i.e. single beam data or depth data derived from a nautical chart, a spatial interpolation process is necessary to generate a $3 \mathrm{D}$ model. Starting from irregular spaced measured points, the depths in unsampled areas must be calculated, using appropriate grid spacing related to the accuracy of the input data [15]. The number of nodes which compose the grid is a variable which impacts on the accuracy of model: the more nodes there are, the better the accuracy will be [16].

Spatial interpolation is a concept strongly linked with Digital Terrain Models (DTMs), introduced by Miller \& Laflamme [17], or more generally with Digital Elevation Models (DEMs). DEMs can be defined as the digital representation of the Earth surface elevation referred to any given geodetic reference system [18], [19]: a 3-dimensional representation of a terrain surface consisting of three-dimensional coordinates (i.e. $E, N$, $h$ or $\lambda, \phi$, $H$ ) stored in digital form [20]. They can be produced in different way, i.e. using $3 \mathrm{D}$ stereoscopic viewing photogrammetric methods [21], [22] or interpolating height points and/or contour lines [23], [24].

Interpolation methods that support DEM generation can be used not only for terrain modelling, but for seabed modelling too. This can be indicated as Digital Depth Model (DDM) because describes the variability of the distance between the sea surface and sea bottom [25].

Several interpolation methods are offered by GIS software to interpolate depth values, each of them has its own advantages and disadvantages [26], but in many cases, the most performing ones result kriging interpolators [24]. They cannot be applied in an automatic way but require to be tested, due to the specificity of the analysed surface morphology that may influence the results [27], and to be supervised by the user to set specific parameters. One of these parameters is the semi-variogram model, that is a graphical representation of the spatial correlation between the measurement points. An approximating function is used instead of the experimental semi-variogram [28], [29].

The aim of this article is to analyse kriging approach, specifically Ordinary kriging and Universal kriging methods, and demonstrate that the level of accuracy that can be achieved depends crucially on the choice of the mathematical model of the semi-variogram.

This paper is organized as follows. Section 2 focuses on the study area and dataset. Section 3 describes: firstly, the main characteristics of the kriging approach based on semi-variance concept, with particular attention to the methodological aspects of Ordinary and Universal kriging, then the analysis process for DDM accuracy evaluation. Section 4 introduces and discusses the results obtained in dependence of the choice of the mathematical function to fit the experimental semi-variogram
(11 different models are compared). Finally, Section 5 presents our conclusions.

\section{STUDY AREA AND DATASET}

The area considered for this study concerns the Bay of Pozzuoli, located north-west of Naples, in the Campania region (Italy), as shown in Figure 1.

In the Bay of Pozzuoli, the inner continental shelf, that extends between $0-40 \mathrm{~m}$ below sea level (b.s.l.), varies significantly, from a few hundred meters at its western side (Baia) to $1.6 \mathrm{~km}$ at its eastern side (between Bagnoli and Nisida), reaching $1.8 \mathrm{~km}$ west of Pozzuoli [30]. In the seabed morphology, gentle slopes prevail, and several terraced surfaces mostly oriented $\mathrm{N} 130^{\circ} \mathrm{E}$ occur: those terraced areas present widths up to $1.5 \mathrm{~km}$ in the easternmost side of the Bay and as small as $0.5 \mathrm{~km}$ in the west [31].

The area is of great interest for many purposes: as a consequence of the overall subsidence starting at the end of the Roman period, the main part of the ancient coastal strip, including all the buildings and maritime structures, is nowadays submerged below the marine surface [32], giving life to the "underwater park of Baia", which is the subject of numerous
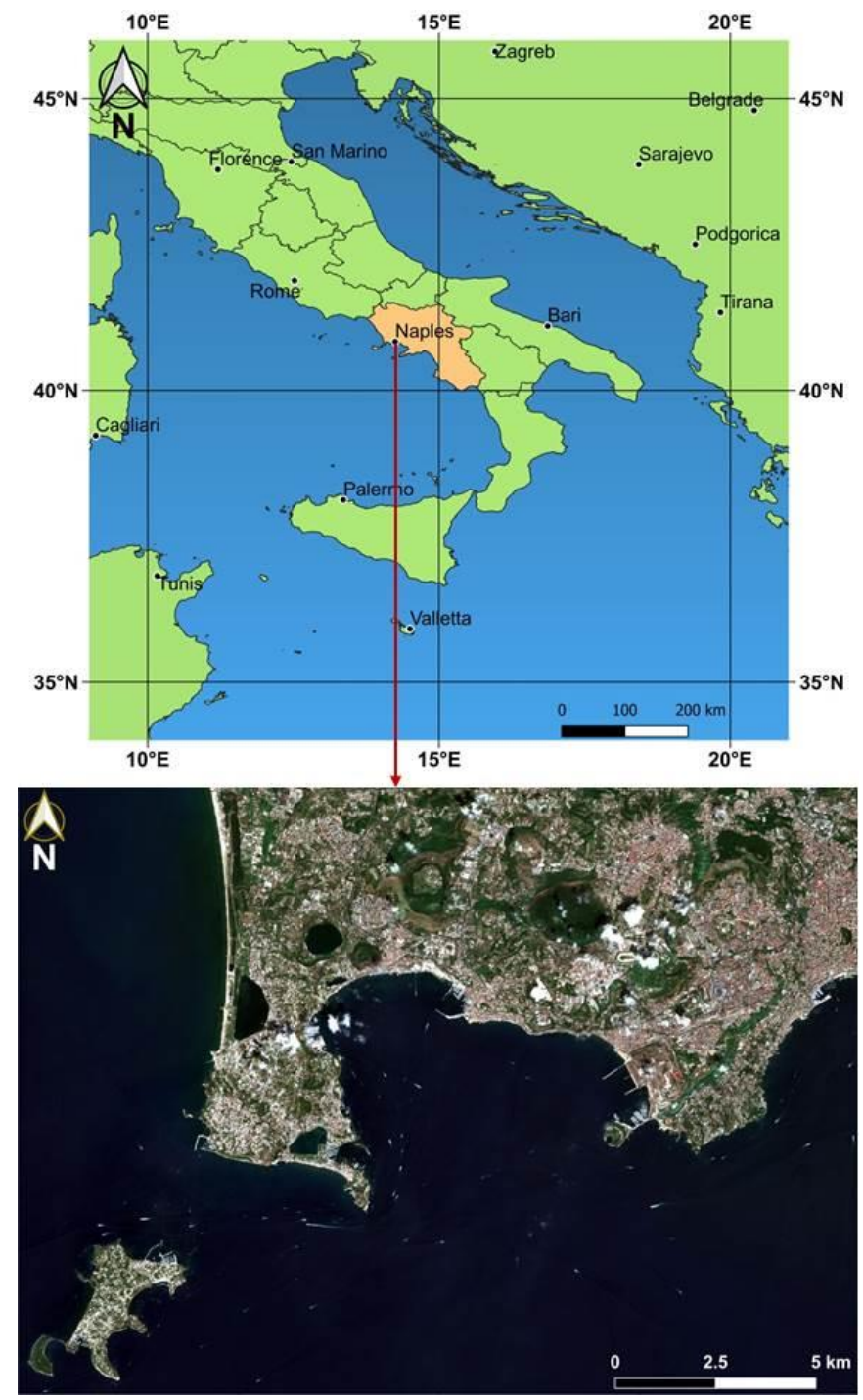

Figure 1. Geo-localization of the Bay of Pozzuoli in the national context (top) and a RGB composition from Sentinel-2 imagery of the Bay of Pozzuoli (bottom). 


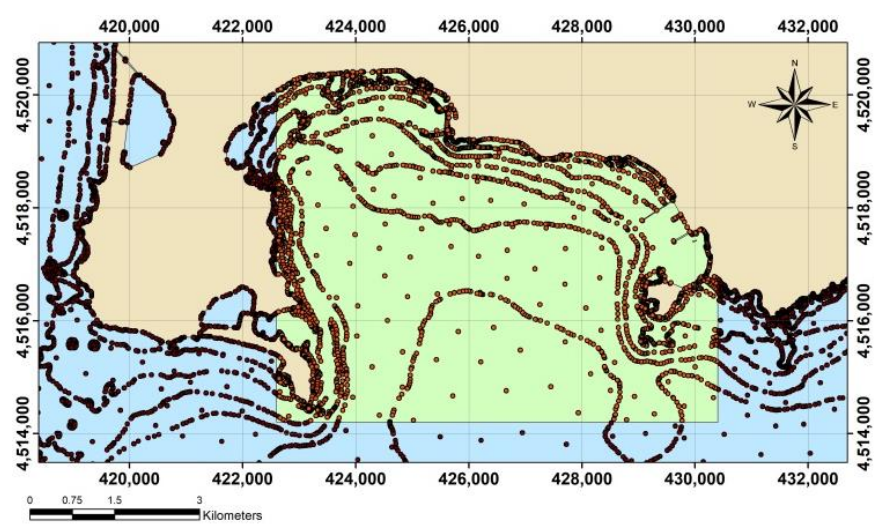

Figure 2. The selected point dataset (in the green rectangle), extracted from ENC depth information of the Bay of Pozzuoli, submitted to Kriging interpolations.

studies including those through underwater acoustics techniques [33], [34].

Moreover, Pozzuoli inland zone and Pozzuoli Bay are included in the active volcanic sector named "Campi Flegrei", corresponding to a densely populated region with complex geological context [35]. As it usually happens in the case of volcanic areas, in addition to the calderas, several fault systems surround the craters in the Gulf of Pozzuoli [36]. Particularly, it is characterized by at least one large caldera collapse structure which extends over an area of $8 \mathrm{~km}$ in diameter in the central sector and is associated with the eruption of the Neapolitan Yellow Tuff (NYT), an ignimbrite deposit dated $15 \mathrm{ka}$ B.P [37]. This exceptional environment, severely sacked over the years, has been included in a Marine Protected Area since 2001 [38].

The seafloor of the Gulf of Pozzuoli has also been largely studied for sedimentological analysis [39], biological research [40], gravimetric measurements [41], sea-level changes [42], marine circulation [43], etc. Furthermore, several bathymetric surveys have been conducted in the Gulf of Pozzuoli [31], [44]; therefore, the area presents excellent conditions for 3D modelling.

Depth data for this work are extracted from two ENCs produced by the IIMM, in scale 1:30.000, identified as $n^{\circ} 129$ and $\mathrm{n}^{\circ} 130$. The two sources are necessary as the area falls half in one and half in the other nautical chart. The original files are formed in accordance with the official standards established by the International Hydrographic Organization (S-57 IHO) [14]. They are transformed in shape file for using them in ArcGIS version 10.3.1 (ESRI) [45]. ENCs are georeferred in WGS84 geodetic datum. The depths are referred to the Mean Lower Low Water (MLLW), which is the average height of the lowest tide recorded at a tide station each day during a recording period [46]. ENCs are classified in six categories or "Zones of Confidence", ranging from high accuracy to poor accuracy at the other end of the spectrum, and one category of "Unassessed" [47]. The considered ENCs are classified D: it means that soundings are similarly sourced from historic surveys, but in this case those conducted with large distances between adjacent survey lines, or simply soundings collected on an opportunity basis by ships undertaking routine passage [48]. In absence of specific indications, we assume this dataset as characterized by nominal scale accuracy. This assumption is not in contradiction with our purpose, that is to establish the effectiveness of the kriging interpolators for bathymetric data in consideration of the map scale.
Firstly, we projected the dataset in the Universal Transverse of Mercator (UTM)/WGS84 Zone 33 N (EPSG code: 32633), and group the vertices of contour lines and the depth points in one shape file; formerly we select from them only ones that fall in the area shown in Figure 2.

This area extends within the following UTM/WGS84 plane coordinates - 33T zone: $\mathrm{E} 1=422,600 \mathrm{~m}, \mathrm{E} 2=430,400 \mathrm{~m}, \mathrm{~N} 1$ $=4,514,200 \mathrm{~m}, \mathrm{~N} 2=4,520,500 \mathrm{~m}$. Depth values range between $0 \mathrm{~m}$ and $-142 \mathrm{~m}$. However, from the same ENCs a less extended area was considered in a previous step of our research and a more limited dataset was extracted for bathymetric modelling applications; the first results were published in [49].

In this study, the resulting 3181 points are used as dataset for the application of the Ordinary and Universal kriging interpolation methods available in Geostatistical Analyst [50], an extension included in ArcGIS software.

\section{METHODOLOGY}

Kriging is founded on the first law of Geography introduced by Waldo R. Tobler's in 1969: "everything is related to everything else, but near things are more related than distant things" [51]. In other words, things closer together are more similar than things further away, so observations made on nearby points actually show less variability than observations made between distant points [52]. Unlike to deterministic methods, kriging applies the geo-statistical model which includes the spatial correlation between sampled points and uses it to estimate the value at an unknown point [53].

Kriging interpolation method assumes that the spatial variation of any continuous attribute is often too irregular to be modelled by a simple mathematical function. The variation can instead be better described by a stochastic surface [54]. In fact, kriging is included in stochastic interpolation approach, that is funded on the assumption that the link between the neighbouring points can be expressed by a statistical relationship, which may have no physical significance [55]. As a result, kriging approach can supply models that better represent and describe the territory variability: the method usually ensures a more reliable prediction of the values in the non-sampled points.

In order to evaluate the variability of the points with increasing distances, the semi-variogram is adopted. The semivariogram is the diagram resulting from the representation of the semi-variance as a function of the distance between two points [56]. Mathematically the semi-variance is given by [57]:

$$
\gamma(h)=\frac{1}{2 n} \sum_{i=1}^{n}\left(z\left(x_{i}\right)-z\left(x_{i}+h\right)\right)^{2},
$$

where $\gamma(h)$ is the value of the semi-variance at the distance $h ; n$ is the number of couples of points separated by $h ; z$ is the value of the depth; $x_{i}$ and $x_{i}+h$ indicate the positions of each couple of points.

To facilitate the procedure and make it faster, the pairs are grouped into lag bins. A good lag size has to be determined for grouping semi-variogram values. In this way, the size of a distance class into which pairs of locations are grouped permits to reduce the large number of possible combinations [58]. Consequently, the semi-variance is calculated for all pairs of points that present distance within a specific range (e.g. 10 meters and 20 meters).

Mathematical models can be used to substitute the empirical semi-variogram, fitting the data in the best way: the standard model that finest approximates the empirical one has to be 
selected, in order to obtain a law that describes the trend of the random variable on the territory throughout the area covered by the samples [59]. This substitution permits to introduce in the kriging process semi-variogram values for lag distances that are not used in the empirical semi-variogram [60].

In kriging interpolation process, different weights are attributed to the measured values and chosen in such a way as to optimize the interpolating function [61]. To determine the weights, various approaches are adopted: this is a peculiar aspect that distinguishes different methods to implement kriging interpolation, as remarked in Section 3.1 and Section 3.2 for the considered Ordinary kriging and Universal kriging. The application of these methods requires to define some parameters as illustrated in Section 3.3.

Because this article is aimed to analyse the role of the semivariogram model in Ordinary kriging as well as in Universal kriging, in Section 3.4 the adopted approach to evaluate the accuracy of the resulting models is illustrated.

\subsection{Ordinary Kriging}

Ordinary kriging is the most widely used kriging method. It assumes the model [62]:

$$
z\left(x_{0}\right)=\sum_{i=1}^{n} \lambda_{i} z\left(x_{i}\right)
$$

where $\lambda_{i}$ are the kriging weights computed from a normal system of equations derived by minimization of the error variance.

The function $z\left(x_{i}\right)$ is composed of a deterministic component $\mu$ and a random function $\varepsilon\left(x_{i}\right)$ [63]:

$$
z\left(x_{i}\right)=\mu+\varepsilon\left(x_{i}\right) \text {. }
$$

The deterministic component is a constant value for each $x_{i}$ location in each search area.

\subsection{Universal Kriging}

The Universal kriging model assumes that the deterministic component can be expressed locally as a linear combination $\sum_{l} a_{l} f^{l}(x)$ of $\mathrm{k}$ known basis functions $f^{l}(x)$ (generally polynomials) with unknown coefficients $a_{l}$ [64]. Equation 3 can be re-written for this method as follow [65]:

$$
z\left(x_{i}\right)=\mu\left(x_{i}\right)+\varepsilon\left(x_{i}\right) \text {. }
$$

If compared with Ordinary kriging this model is in general more difficult to implement [66].

\subsection{Parameter settings}

To apply Ordinary kriging as well as Universal kriging, the user must define some parameters. First of all, the points involved in the estimation of depth value in each prediction location have to be established. According to the first law of Geography, the user can take into account that the correlation of the measured values with the prediction value depends on the distance that separates dataset points from grid node and decreases as the distance increases. Consequently, a search neighbourhood is necessary to exclude far points from the interpolation process to predict the depth at a specific location. The user defines shape and dimensions of the neighbourhood: in our experiments, an equal influence on the grid node is attributed to the surrounding points, so the same dimension of search is fixed for both semi-axis (isotropic model). The fixed value for the search radius defines the number of the points included in the neighbourhood.

The search radius is not the only parameter to define. In addition, the user can divide the search area into sectors and

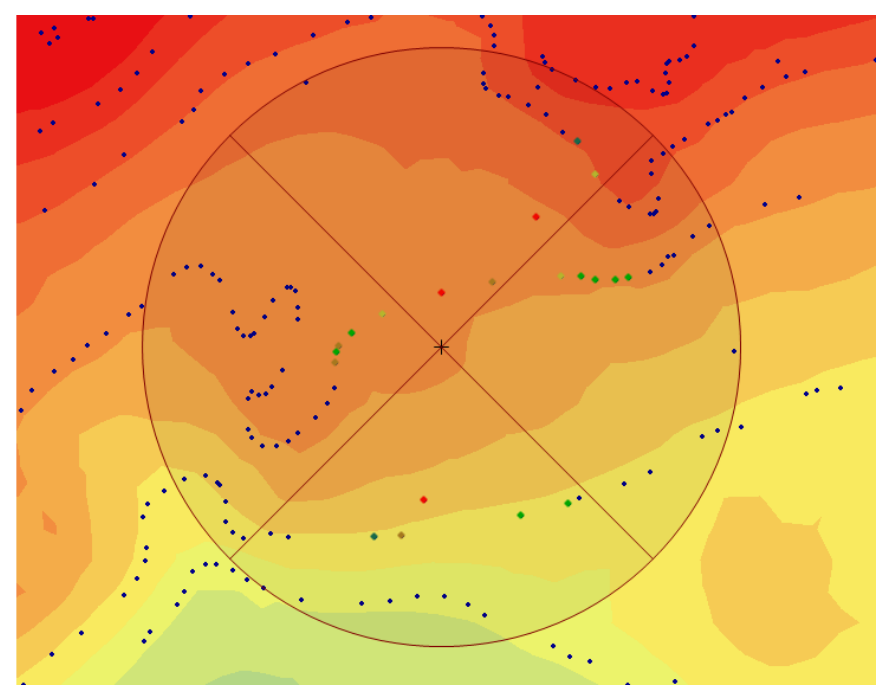

Figure 3. Searching neighbourhood step for Ordinary kriging application.

ensure a minimum and a maximum number of surrounding points to be included in the interpolation process. However, the definition of the range of the surrounding point number is possible also in the case of a unique neighbourhood without sector division [67]. In our study, four sectors with an offset of $45^{\circ}$ are used. An example of searching neighbourhood step for Ordinary kriging application is shown in Figure 3.

The dialog box of the software for kriging application, usually permits to set also number and size of the lags to group semivariogram values.

\subsection{Cross-Validation}

In order to evaluate the accuracy of each method, crossvalidation is adopted. It allows to define the level of accuracy of the predicted values by distinguishing between training set and validation set, the first used for model generation, the second for model evaluation [68]. There are several cross-validation approaches, among which one of the most adopted is the leaveone-out method. Leave-one-out method is based on the removal of a point from the data to be interpolated, the use of the other points to estimate a value at the location of the removed point, and the performance test by means of the removed data [69]. To evaluate the performance of the selected interpolation method, the difference between the known value and the estimated value in each removed point is calculated [70].

For the experiments carried out in this study, the residuals are treated with a statistical approach, obtaining minimum, maximum, mean, standard deviation and root mean square error (RMSE).

\section{RESULTS AND DISCUSSION}

In this study, Ordinary and Universal kriging are applied to the chosen dataset by varying all mathematical semi-variogram models available in Geostatistical Analyst. Specifically, the following models are adopted:

- Gaussian Model (GAM),

- Circular Model (CIM),

- Exponential Model (EXM),

- Spherical Model (SPM),

- Tetraspherical Model (TEM),

- Pentaspherical Model (PEM),

- $\quad$ Stable Model (STM), 


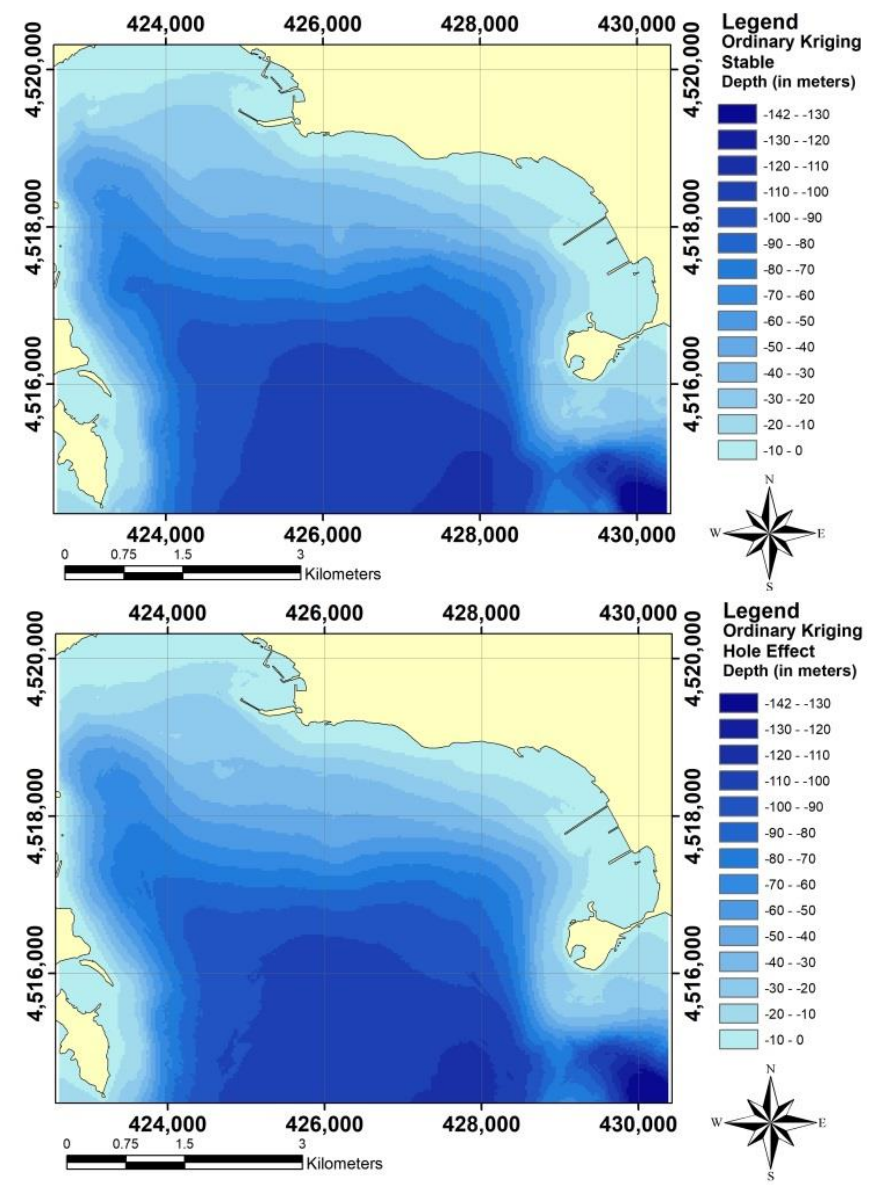

Figure 4. 2D bathymetric models resulting for Ordinary kriging approach from the application of Stable Semi-Variogram Model (top) and Hole Effect SemiVariogram Model (bottom).

- J-Bessel Model (JBM),

- K-Bessel Model (KBM),

- Rational Quadratic Model (RQM), and

- Hole Effect Model (HEM).

Those models are described in the literature and some of them are very recurrent in kriging applications, so the readers could referrer to specific papers on this matter, e.g. [71]-[74].

To define the cell size of each model, the ENC scale is considered. On this aspect several suggestions are available in literature. On the question of cell size definition for each raster map, Waldo Tobler [75] advised that the rule is: divide the denominator of the map scale by 1,000 to get the detectable size in meters; the resolution is one half of this amount. Valenzuela and Baumgardner recommended cell sizes ranging from $0.5 \mathrm{~mm} \times 0.5 \mathrm{~mm}$ to $3 \mathrm{~mm} \times 3 \mathrm{~mm}$ on the map when dealing with thematic maps in a raster-based GIS [76]. Relating grid resolution to cartographic concepts, Tomislav Hengl [77] proposed the following formulas for finding the right pixel size $p$ (in meters) for DTM:

$$
\begin{aligned}
& p \leq S N \cdot 0.0025 \mathrm{~m} \\
& p \geq S N \cdot 0.0001 \mathrm{~m},
\end{aligned}
$$

where $S N$ is scale factor. He also suggested the following formula as a good compromise:

$$
p=S N \cdot 0.0005 \mathrm{~m} \text {. }
$$

In this application, considering also the ENC poor accuracy $(\mathrm{ZOC}=\mathrm{D})$ we fixed the cell at $30 \mathrm{~m}$ for the generated DDMs.

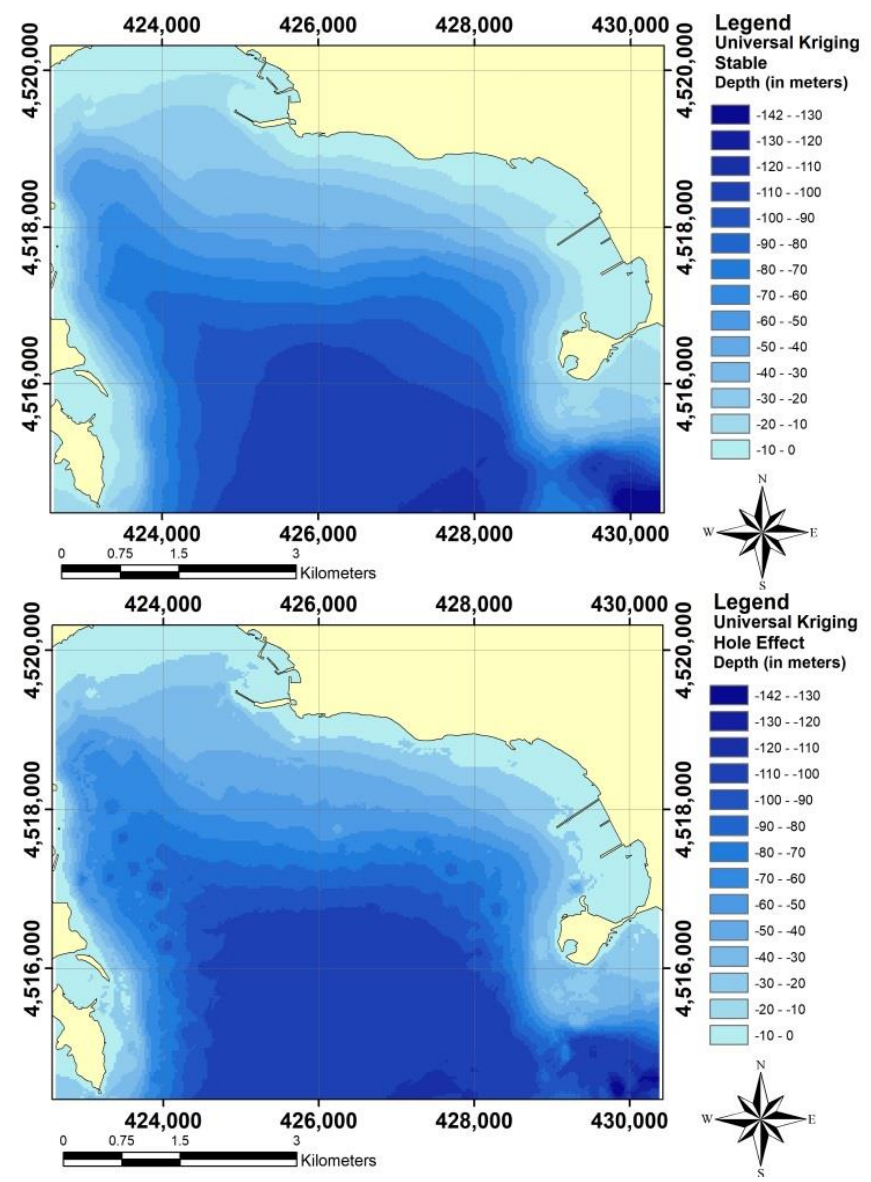

Figure 5. 2D bathymetric models resulting for Universal kriging approach from the application of Stable Semi-Variogram Model (top) and Hole Effect Semi-Variogram Model (bottom).

Using all semi-variogram models available, eleven grids are generated for each kriging method. In the case of the Ordinary kriging, a number of lag equal to 12 is chosen with a lag size of $290 \mathrm{~m} \mathrm{[78]} \mathrm{and} \mathrm{an} \mathrm{isotropic} \mathrm{search} \mathrm{radius} \mathrm{of} 2300 \mathrm{~m}$ [67]. In the case of the Universal kriging, a number of lag equal to 12 is chosen with a lag size of $72 \mathrm{~m}$ and an isotropic search radius of $570 \mathrm{~m}$.

In Figure 4, 2D representations of 2 bathymetric models georeferred in UTM-WGS84 plane coordinates, concerning the Ordinary kriging applications are reported. Particularly, the upper concerns the most performing model resulting from STM application, the lower concerns the worst performing model resulting from HEM application.

In the same way, in Figure 5, 2D representations of 2 bathymetric models georeferred in UTM-WGS84 plane coordinates, concerning the Universal kriging applications are reported. Also in this case, the upper concerns the most performing model resulting from STM application, the lower concerns the worst performing model resulting from HEM application.

In Figure 6 to Figure 9, four examples of semi-variogram generated for Ordinary kriging applications, respectively by STM (first), HEM (second), EXM (third), SPM (forth) are shown.

Significant statistical parameters (minimum, maximum, mean, standard deviation and root mean square error) of all residuals for each semi-variogram mathematical function are shown in Table 1 for Ordinary kriging applications and in Table 2 for Universal kriging applications. 


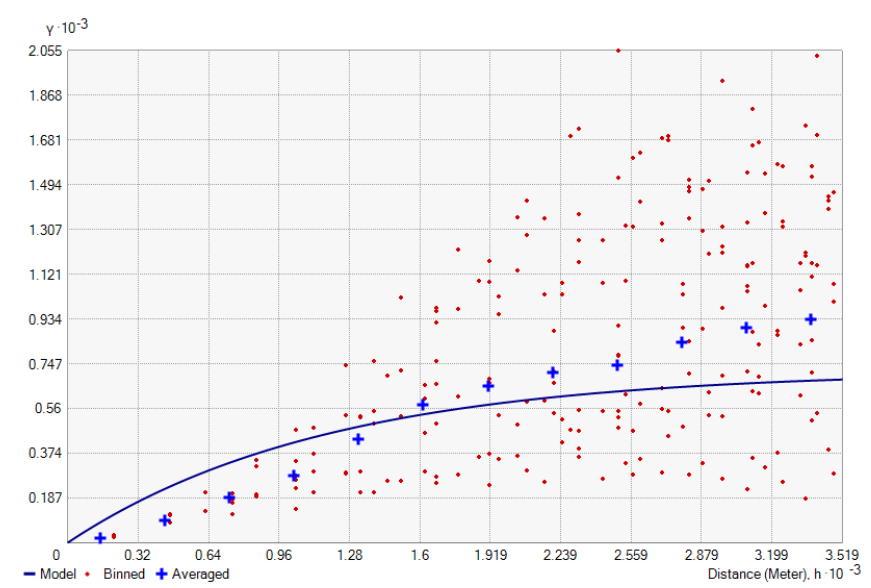

Figure 6. Example of semi-variogram generated for Ordinary kriging application based on the Exponential model.

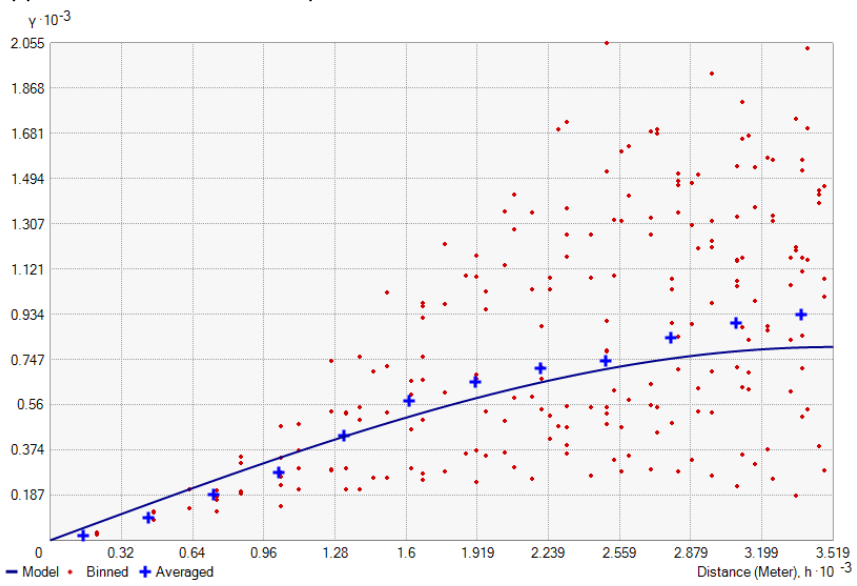

Figure 7. Example of semi-variogram generated for Ordinary kriging application based on the Exponential model.

The 3D visualization of the most performing bathymetric model, generated by Ordinary kriging interpolator with STM, is shown in Figure 10.

Note that the depth values have been multiplied for amplifying factor equal to 3 , so as to enhance the visualization of seabed morphology. The results of the elaborations demonstrate the different levels of accuracy than can be achieved in dependence of the choice of the semi-variogram model for both kriging approaches.

For Ordinary kriging the range of minimum values goes from -11.916 m obtained for KBM, to $-16.703 \mathrm{~m}$ resulting from EXM.

Table 1. Statistical terms of the residuals supplied by Cross validation for the Ordinary kriging.

\begin{tabular}{cccccc}
\hline Model & Min $(\mathbf{m})$ & Max $(\mathbf{m})$ & $\begin{array}{c}\text { Mean } \\
(\mathbf{m})\end{array}$ & $\begin{array}{c}\text { St.Dev } \\
(\mathbf{m})\end{array}$ & $\begin{array}{c}\text { RMSE } \\
(\mathbf{m})\end{array}$ \\
\hline GAM & -13.973 & 12.039 & -0.142 & 1.699 & 1.705 \\
CIM & -15.830 & 15.158 & 0.064 & 1.450 & 1.451 \\
EXM & -16.703 & 15.612 & 0.074 & 1.482 & 1.484 \\
SPM & -15.814 & 15.168 & 0.064 & 1.448 & 1.449 \\
TEM & -15.800 & 15.186 & 0.063 & 1.447 & 1.448 \\
PEM & -15.790 & 15.212 & 0.063 & 1.446 & 1.447 \\
STM & -13.440 & 12.717 & 0.008 & 1.280 & 1.280 \\
JBM & -13.226 & 13.254 & -0.145 & 1.717 & 1.723 \\
KBM & -11.916 & 12.000 & -0.085 & 1.463 & 1.465 \\
RQM & -14.456 & 14.627 & -0.060 & 1.456 & 1.457 \\
HEM & -15.051 & 14.746 & -0.152 & 1.781 & 1.787 \\
\hline
\end{tabular}

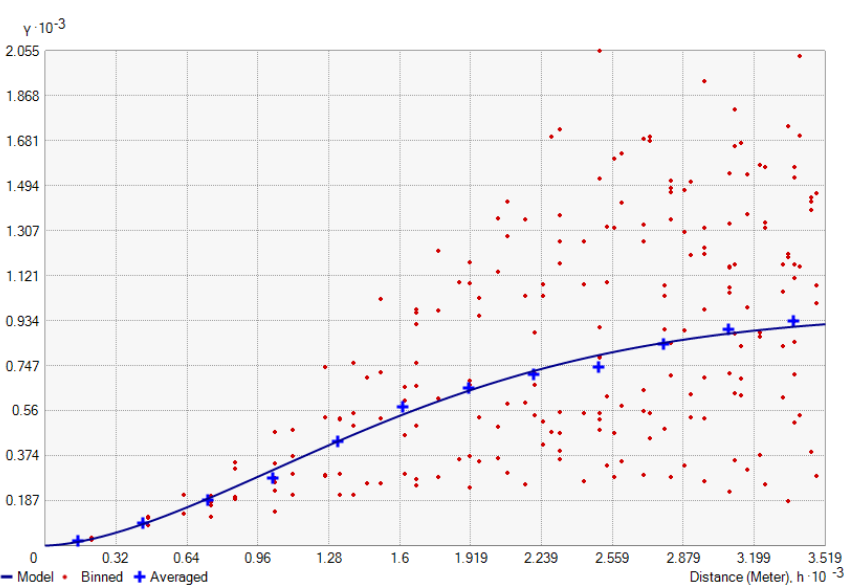

Figure 8. Example of semi-variogram generated for Ordinary kriging application based on the Stable model.

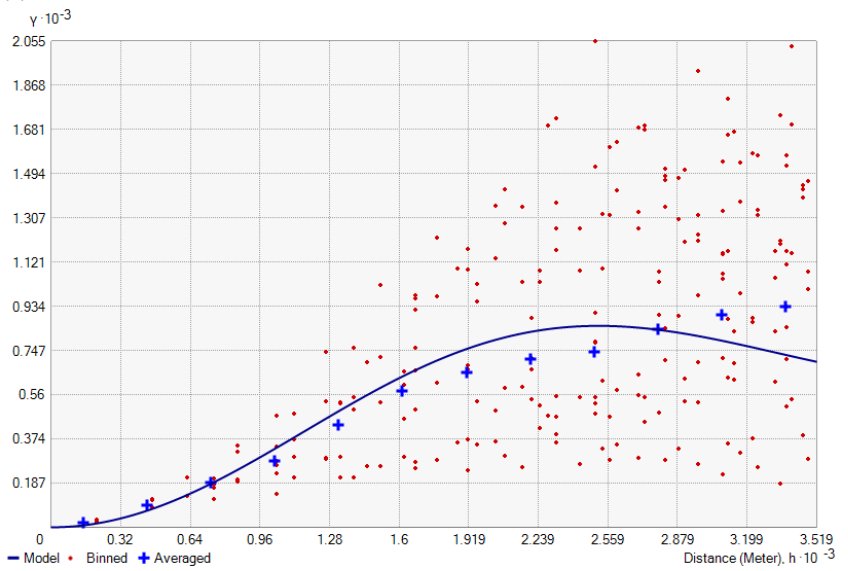

Figure 9. Example of semi-variogram generated for Ordinary kriging application based on the Hole Effect model.

The range of maximum values goes from $12.000 \mathrm{~m}$ obtained for $\mathrm{KBM}$, to $15.612 \mathrm{~m}$ resulting from EXM. The range of mean values goes from $-0.152 \mathrm{~m}$ obtained for HEM, to $0.074 \mathrm{~m}$ resulting from EXM. The range of standard deviation goes from $1.280 \mathrm{~m}$ for STM to $1.781 \mathrm{~m}$ resulting from HEM. The range of RMSE goes from $1.280 \mathrm{~m}$ for STM to $1.787 \mathrm{~m}$ resulting from HEM. By analyzing the RMSE values, STM seems to be the most performing semi-variogram model, while HEM supplies the worst results.

For Universal kriging the range of minimum values goes from $-13.739 \mathrm{~m}$ obtained for TEM, to $-16.361 \mathrm{~m}$ resulting from JBM.

Table 2. Statistical terms of the residuals supplied by Cross validation for the Universal kriging.

\begin{tabular}{cccccc}
\hline Model & Min $(\mathbf{m})$ & Max $(\mathbf{m})$ & Mean $(\mathbf{m})$ & St.Dev $(\mathbf{m})$ & RMSE (m) \\
\hline GAM & -16.351 & 16.652 & 0.067 & 1.524 & 1.525 \\
CIM & -13.995 & 15.630 & 0.066 & 1.438 & 1.440 \\
EXM & -14.371 & 15.395 & 0.082 & 1.476 & 1.478 \\
SPM & -13.827 & 15.283 & 0.066 & 1.435 & 1.437 \\
TEM & -13.739 & 15.460 & 0.069 & 1.444 & 1.446 \\
PEM & -14.093 & 15.560 & 0.072 & 1.452 & 1.454 \\
STM & -14.158 & 15.232 & 0.074 & 1.426 & 1.428 \\
JBM & -16.361 & 17.083 & 0.065 & 1.535 & 1.536 \\
KBM & -14.353 & 15.284 & 0.079 & 1.430 & 1.432 \\
RQM & -15.523 & 15.716 & 0.075 & 1.488 & 1.490 \\
HEM & -15.435 & 19.163 & 0.062 & 1.578 & 1.579 \\
\hline
\end{tabular}




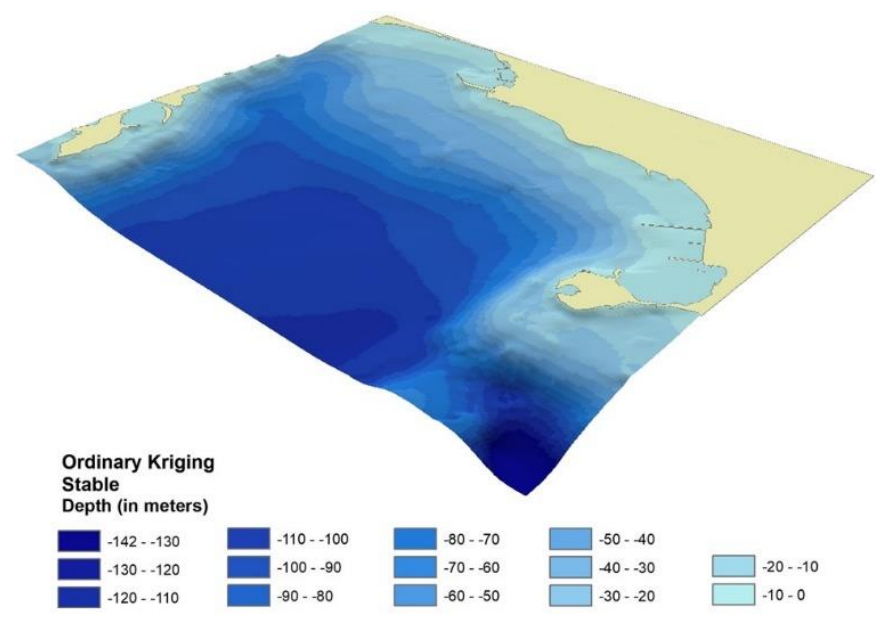

Figure 10. 3D visualization of the most performing bathymetric mode generated by Ordinary kriging - STM.

The range of maximum values goes from $15.232 \mathrm{~m}$ obtained for STM, to $19.163 \mathrm{~m}$ resulting from HEM. The range of mean values goes from $0.062 \mathrm{~m}$ obtained for HEM, to $0.082 \mathrm{~m}$ resulting from EXM. The range of standard deviation goes from $1.426 \mathrm{~m}$ for STM to $1.578 \mathrm{~m}$ resulting from HEM. The range of RMSE goes from $1.428 \mathrm{~m}$ for STM to $1.579 \mathrm{~m}$ resulting from HEM. By analyzing the RMSE values, also in this case, STM seems to be the most performing semi-variogram model, while HEM supplies the worst results. In every case, RMSE values are acceptable in consideration of the accuracy of the ENCs from which the depth data are derived.

The best performance of STM obtained in this case study cannot be generalized. In other words, the comparison offers the possibility to establish in this specific case that STM offers the best performance, but it cannot be asserted that it will always be so.

\section{CONCLUSIONS}

The particular relevance of the study area, the Bay of Pozzuoli, in many fields, e.g. geology, archaeology and natural science, makes clear that accurate bathymetric models are fundamental to support studies and application.

A first source of information about seabed morphology is included in ENC: profundity information contained in isolines and depth points is useful to realize $3 \mathrm{D}$ models of the seabottom. To achieve this result, particular attention must be reserved to the interpolation approach to derive continuous model from cloud point dataset.

The present research remarks the high performance of both the Kriging approaches for this purpose and demonstrates the relevance of the choice of the mathematical model to build the semi-variogram for Ordinary kriging as well as Universal kriging.

As tested by using leave-one-out cross validation, different levels of accuracy can be achieved in dependence of the function used to substitute the empirical semi-variogram, fitting the depth data in the best way. By analysing residuals between measured and interpolated values of bathymetric depths, it is possible to identify the best performing 3D model of seabed in the study area.

The approach adopted for the Bay of Pozzuoli can be used each time bathymetric data are available and usable for 3D model of seabed. In this way, the choice of the most suitable semi- variogram model supports the user to achieve a more performing 3D bathymetric model.

Appling kriging methods, the specificity of the considered area, as well as the distribution of the dataset points influence the quality of the results, so it is impossible to define in an absolute way the most effective semi-variogram model to be adopted. RMSE analysis carried out on residuals resulting from leave-oneout cross validation remains the best approach to compare different mathematical functions for semi-variogram construction.

\section{ACKNOWLEDGEMENT}

This work synthesizes results of experiments executed within a research project performed in the Laboratory of Geomatics, Remote Sensing and GIS of the "Parthenope" University of Naples. We would like to thank the technical staff for their support.

\section{REFERENCES}

[1] J. Duan, X. Wan, J. Luo, Research on the hydrographic survey cycle for updating navigational charts, The Journal of Navigation 74(4) (2021), pp. 1-13.

DOI: $10.1017 /$ S0373463320000776

[2] K. V. Sanilkumar, T. V. Kuruvilla, D. Jogendranath, R. R. Rao, Observations of the Western Boundary Current of the Bay of Bengal from a hydrographic survey during March 1993, Deep Sea Research Part I: Oceanographic Research Papers 44(1) (1997), pp. 135-145. DOI: $10.1016 /$ S0967-0637(96)00036-2

[3] G. D'Onghia, F. Capezzuto, R. Carlucci, A. Carluccio, P. Maiorano, M. Panza, P. Ricci, L. Sion, A. Tursi, Using a benthic lander to explore and monitor vulnerable ecosystems in the Mediterranean Sea, ACTA Imeko 7(2) (2018), pp. 45-49.

DOI: $10.21014 /$ acta imeko.v7i2.544

[4] G. Kågesten, D. Fiorentino, F. Baumgartner, L. Zillén, How Do Continuous High-Resolution Models of Patchy Seabed Habitats Enhance Classification Schemes? Geosciences 9(5) (2019), pp. 237. DOI: $10.3390 /$ geosciences9050237

[5] A. I. El-Hattab, Single beam bathymetric data modelling techniques for accurate maintenance dredging, The Egyptian Journal of Remote Sensing and Space Science 17(2) (2014), pp. 189-195. DOI: $10.1016 /$ j.ejrs.2014.05.003

[6] M. Specht, C. Specht, J. Mindykowski, P. Dabrowski, R. Masnicki, A. Makar, Geospatial Modeling of the Tombolo Phenomenon in Sopot using Integrated Geodetic and Hydrographic Measurement Methods, Remote Sensing 12(4) (2020), pp. 737.

DOI: $10.3390 / \mathrm{rs} 12040737$

[7] L. Sinapi, L. Lamberti, N. Pizzeghello, R. Ivaldi, R. Italian Hydrographic Institute (IIM), Genoa (ITALY), International Hydrographic review, (2016).

[8] A. Ceylan, H. Karabork, I. Ekozoglu, An analysis of bathymetric changes in Altinapa reservoir, Carpathian Journal of Earth and Environmental Sciences, 6(2), (2011), pp. 15-24. Online [Accessed 31 August 2021] http://www.cjees.ro/actions/actionDownload.php?fileId=176

[9] I. Parnum, J. Siwabessy, A. Gavrilov, M. Parsons, A comparison of single beam and multibeam sonar systems in seafloor habitat mapping, Proc. 3rd Int. Conf. and Exhibition of Underwater Acoustic Measurements: Technologies \& Results, Nafplion, Greece, 2009, June, pp. 155-162.

[10] C. Parente, M. Pepe, Bathymetry from worldView-3 satellite data using radiometric band ratio, Acta Polytechnica 58(2) (2018), pp. 109-117.

DOI: $\underline{10.14311 / A P .2018 .58 .0109}$ 
[11] M. Alicandro, V. Baiocchi, R. Brigante, F. Radicioni, Automatic Shoreline Detection from Eight-Band VHR Satellite Imagery, Journal of Marine Science and Engineering 7(12) (2019), pp. 459. DOI: $10.3390 /$ imse 7120459

[12] N. Chukwu Fidelis, O. T. Badejo, Bathymetric survey investigation for lagos lagoon seabed topographical changes, Journal of Geosciences 3(2) (2015), pp. 37-43.

DOI: $10.12691 /$ igg-3-2-2

[13] D. Brčić, S. Kos, S. Žuškin, Navigation with ECDIS: Choosing the proper secondary positioning source. TransNav: International Journal on Marine Navigation and Safety of Sea Transportation 9 (2015).

DOI: $10.12716 / 1001.09 .03 .03$

[14] IHO, IHO transfer standard for digital hydrographic data Edition 3.1 - November 2000, Special Publication No. 57, (2000), International Hydrographic Bureau, ONACO.

[15] J. W. Chung, J. D. Rogers, Interpolations of groundwater table elevation in dissected uplands. Groundwater 50(4) (2012), pp. 598 607.

DOI: $10.1111 / \mathrm{i} .1745-6584.2011 .00889 . \mathrm{x}$

[16] R. Sassais, A. Makar, Methods to Generate Numerical Models of Terrain for Spatial ENC Presentation. Annual of Navigation 18 (2011), pp. 69-81. Online [Accessed 31 August 2021]

http://yadda.icm.edu.pl/baztech/element/bwmeta1.element.baz tech-352ef1e4-201c-4b6b-9f37-

500ee2c9e4e9/c/Sassais.pdfhttp://vadda.icm.edu.pl/baztech/ele ment/bwmeta1.element.baztech-352ef1e4-201c-4b6b-9f37500ee2c9e4e9/c/Sassais.pdf

[17] C. L. Miller, R. A. Laflamme, The Digital Terrain Model: Theory \& Application, MIT Photogrammetry Laboratory (1958).

[18] A. Balasubramanian, Digital elevation model (DEM) in Gis. University of Mysore (2017).

[19] D. C. Guastella, L. Cantelli, D. Longo, C. D. Melita, G. Muscato, Coverage path planning for a flock of aerial vehicles to support autonomous rovers through traversability analysis. ACTA Imeko 8(4) (2019), pp. 9-12.

DOI: $10.21014 /$ acta imeko.v8i4.680

[20] E. Alcaras, U. Falchi, C. Parente, Digital Terrain Model Generalization for Multiscale Use, International Review of Civil Engineering (IRECE) 11(2) (2020), pp.52-59. DOI: $\underline{10.15866 / \text { irece.v11i2.17815 }}$

[21] R. Amato, G. Dardanelli, D. Emmolo, V. Franco, M. Lo Brutto, P. Midulla, P. Orlando, B. Villa, Digital orthophotos at a scale of 1: 5000 from high resolution satellite images. ISPRS Journal of Photogrammetry \& Remote Sensing, Istanbul, Turkey, 12-23 July 2004, pp. 593-598.

[22] N. Cenni, S. Fiaschi, M. Fabris, Integrated use of archival aerial photogrammetry, GNSS, and InSAR data for the monitoring of the Patigno landslide (Northern Apennines, Italy). Landslides, (2021), pp. 1-17. DOI: $10.1007 / \mathrm{s} 10346-021-01635-3$

[23] A. Carrara, G. Bitelli, R. Carla, Comparison of techniques for generating digital terrain models from contour lines, International Journal of Geographical Information Science, 11(5), (1997), pp. 451-473.

DOI: $10.1080 / 136588197242257$

[24] E. Alcaras, C. Parente, A. Vallario, A Comparison of different interpolation methods for DEM production, International Journal of Advanced Trends in Computer Science and Engineering 6 (2019), pp. 1654-1659.

DOI: $10.30534 /$ ijatcse/2019/91842019

[25] C. Parente, A. Vallario, Interpolation of Single Beam Echo Sounder Data for 3D Bathymetric Model, International Journal of Advanced Computer Science and Applications 10(10) (2019) pp. 6-13. DOI: $10.14569 /$ IJACSA.2019.0101002

[26] R. Dupuy, A. Makar, Analysis of Digital Sea Bottom Models Generated using ENC Data, Annual of Navigation 18 (2011), pp. $27-36$. https://www.infona.pl/resource/bwmeta1.element.baztech6fdd414b-7436-4dc6-82e1-2c8a866f0993\#

[27] E. Alcaras, L. Carnevale, C. Parente, Interpolating single-beam data for sea bottom GIS modelling, Int. J. Emerg. Trends Eng. Res. 8 (2020), pp. 591-597. DOI: $10.30534 /$ ijeter/2020/50822020

[28] G. Matheron, Trate de geostatistique appliqde: Mbmoires du Bureau de Recherches Geologiques et Mini\&es, vol. 14, Editions Technip, Paris, (1962), pp. 333.

[29] R. A. Olea, Fundamentals of semivariogram estimation, modeling, and usage, in Stochastic Modeling and Geostatistics, (1994), Eds Jeffrey M. Yarus and Richard L. Chambers.

[30] M. Sacchi, F. Pepe M. Corradino, D. D. Insinga, F. Molisso, C. Lubritto, The Neapolitan Yellow Tuff caldera offshore the Campi Flegrei: Stratal architecture and kinematic reconstruction during the last 15 ky, Marine Geology 354 (2014), pp.15-33. DOI: $10.1016 /$ i.margeo.2014.04.012

[31] R. Somma, S. Iuliano, F. Matano, F. Molisso, S. Passaro, M. Sacchi, C. Troise, G. De Natale, High-resolution morpho-bathymetry of Pozzuoli Bay, southern Italy, Journal of Maps 12(2) (2016), pp. 222-230.

DOI: $\underline{10.1080 / 17445647.2014 .1001800}$

[32] P. P. Aucelli, G. Mattei, C. Caporizzo, A. Cinque, S. Troisi, F. Peluso, M. Stefanile, G. Pappone, Ancient coastal changes due to ground movements and human interventions in the Roman Portus Julius (Pozzuoli Gulf, Italy): Results from photogrammetric and direct surveys, Water 12(3) (2020), pp. 658. DOI: $10.3390 / \mathrm{w} 12030658$

[33] B. D. Petriaggi, G. G. de Ayala, Laser scanner reliefs of selected archeological structures in the submerged Baiae (Naples), The International Archives of Photogrammetry, Remote Sensing and Spatial Information Sciences 40(5) (2015), pp. 79. DOI: $10.5194 /$ isprsarchives-XL-5-W5-79-2015

[34] F. Bruno, A. Lagudi, A. Gallo, M. Muzzupappa, B. D. Petriaggi, S. Passaro, 3D documentation of archeological remains in the underwater park of Baiae, The International Archives of Photogrammetry, Remote Sensing and Spatial Information Sciences 40(5) (2015), pp. 41.

DOI: 10.5194/isprsarchives-XL-5-W5-41-2015

[35] M. Sacchi, S. Passaro, F. Molisso, F. Matano, L. Steinmann, V. Spiess, ... G. Ventura, The holocene marine record of unrest, volcanism, and hydrothermal activity of Campi Flegrei and Somma-Vesuvius. In Vesuvius, Campi Flegrei, and Campanian Volcanism (2020), pp. 435-469. DOI: $10.1016 / \mathrm{B} 978-0-12-816454-9.00016-X$

[36] L. Lirer, G. Luongo, R. Scandone, On the volcanological evolution of Campi Flegrei. Eos, Transactions American Geophysical Union 68(16) (1987), pp. 226-234.

[37] S. Carlino, R. Somma, Eruptive versus non-eruptive behaviour of large calderas: The example of Campi Flegrei caldera (southern Italy), Bulletin of Volcanology 72(7) (2010), pp. 871-886. DOI: $10.1007 / \mathrm{s} 00445-010-0370-\mathrm{V}$

[38] M. Stefanile, Underwater Cultural Heritage, Tourism and Diving Centers. The case of Pozzuoli and Baiae (Italy), In IKUWA V. Congreso Internacional de Arqueología Subacuática. Un patrimonio para la humanidad, Cartagena, 15-18 de octubre de 2014, (2016), pp. 213-224.

[39] S. Innangi, R. Tonielli, G. Di Martino, A. Guarino, F. Molisso, M. Sacchi, High-resolution seafloor sedimentological mapping: the case study of Bagnoli-Coroglio site, Gulf of Pozzuoli (Napoli), Italy, Chemistry and Ecology 36(6) (2020), pp. 511-528. DOI: $10.1080 / 02757540.2020 .1732942$

[40] S. Ricci, C. S. Perasso, F. Antonelli, B. D. Petriaggi, Marine bivalves colonizing Roman artefacts recovered in the Gulf of Pozzuoli and in the Blue Grotto in Capri (Naples, Italy): boring and nestling species, International Biodeterioration \& Biodegradation 98 (2015), pp. 89-100. DOI: $10.1016 /$ i.ibiod.2014.12.001 
[41] G. Berrino, G. Corrado, G. Luongo, B. Toro, Ground deformation and gravity changes accompanying the 1982 Pozzuoli uplift, Bulletin volcanologique 47(2) (1984), pp. 187-200. DOI: $10.1007 / \mathrm{BF} 01961548$

[42] A. D'Argenio, T. Pescatore, M. R. Senatore, Sea-level change and volcano-tectonic interplay, The Gulf of Pozzuoli (Campi Flegrei, Eastern Tyrrhenian Sea) during the last $39 \mathrm{ka}$. Journal of volcanology and geothermal research 133(1-4) (2004), pp. 105121.

\section{DOI: 10.1016/S0377-0273(03)00393-7}

[43] P.de Ruggiero, G. Esposito, E. Napolitano, R. Iacono, S. Pierini, E. Zambianchi, Modelling the marine circulation of the Campania coastal system (Tyrrhenian Sea) for the year 2016: Analysis of the dynamics. Journal of Marine Systems 210 (2020), pp. 103388. DOI: $10.1016 /$ i.jimarsys.2020.103388

[44] S. Passaro, M. Barra, R. Saggiomo, S. Di Giacomo, A. Leotta, H. Uhlen, S. Mazzola, Multi-resolution morpho-bathymetric survey results at the Pozzuoli-Baia underwater archaeological site (Naples, Italy), Journal of Archaeological Science 40(2), (2013), pp. 1268-1278.

DOI: $10.1016 /$ i.jas.2012.09.035

[45] Esri, ArcGIS 10.3, Redlands, CA, USA. Online [Accessed 30 August 2021] www.esri.com/software/arcgis

[46] L. Surace, La georeferenziazione delle informazioni territoriali, Bollettino di Geodesia e Scienze Affini 57(2) (1998), pp. 181-234 (in Italian).

[47] IHO, Mariners' Guide to Accuracy of Depth Information in Electronic Navigational Charts (ENC), Edition 1.0.0, September (2020). Online [Accessed 31 August 2021] https://iho.int/uploads/user/Services $\% 20$ and $\% 20$ Standards/H $\underline{\mathrm{SSC} / \mathrm{HSSC} 12 / \mathrm{S}-}$

67\%20Ed $\% 20100 \% 20$ Mariners $\% 20$ Guide $\% 20$ to $\% 20$ Accuracy $\%$ 20of $\% 20$ Depth $\% 20$ Information $\% 20$ in $\% 20$ ENC.pdf

[48] IHO, Mariners' Guide to Accuracy of Electronic Navigational Charts (ENC) Edition 0.5, July (2017). Online [Accessed 31 August 2021.

https://iho.int/uploads/user/Services $\% 20$ and $\% 20$ Standards/D QWG/Letters/S67\%20Mariners $\% 20$ guide $\% 20$ to $\% 20$ accuracy $\% 20$ of $\% 20$ ENC $\% 2$ $\underline{0 \mathrm{v} 0.5 . \mathrm{pdf}}$

[49] E. Alcaras, C. Parente, A. Vallario, Kriging interpolation of bathymetric data for 3D model of the Bay of Pozzuoli (Italy), 2020 IMEKO TC-19 International Workshop on Metrology for the Sea, Naples, Italy, October 5-7, 2020, pp. 218-223. Online [Accessed 31 August 2021]

https://www.imeko.org/publications/tc19-Metrosea2020/IMEKO-TC19-MetroSea-2020-41.pdf

[50] ESRI, Geostatistical Analyst, ArcGIS 10.3- Help, Redlands, CA, USA. Online [Accessed 30 August 2021] https://desktop.arcgis.com/en/arcmap/latest/extensions/geost atistical-analyst/what-is-arcgis-geostatistical-analyst-.htm

[51] W. R. Tobler, A computer movie simulating urban growth in the Detroit region, Economic geography 46-1 (1970), pp. 234-240.

[52] J. P. Chiles, P. Delfiner, Geostatistics: modeling spatial uncertainty 497 (2009), John Wiley \& Sons.

[53] K. Krivoruchko, Empirical bayesian kriging. ArcUser Fall 6(10) (2012). Online [Accessed 31 August 2021] https://www.esri.com/NEWS/ARCUSER/1012/files/ebk.pdf

[54] M. A. Oliver R. Webster, Kriging: a method of interpolation for geographical information systems, International Journal of Geographical Information Systems 4(3) (1990), pp. 313-332. DOI: $10.1080 / 02693799008941549$

[55] S. Salekin, J. H. Burgess, J. Morgenroth, E. G. Mason, D. F. Meason, A comparative study of three non-geostatistical methods for optimising digital elevation model interpolation, ISPRS international journal of geo-information 7(8) (2018), pp. 300. DOI: $\underline{10.3390 / \text { iigi } 7080300}$
[56] X. Jian, R. A. Olea, Y. S. Yu, Semivariogram modeling by weighted least squares. Computers \& Geosciences 22(4) (1996), pp. 387397. DOI: 10.1016/0098-3004(95)00095-X

[57] C. A. Rishikeshan, S. K. Katiyar, V. N. Vishnu Mahesh, Detailed evaluation of DEM interpolation methods in GIS using DGPS data, International Conference on Computational Intelligence and Communication Networks, Bhopal, India, 14-16 Nov. 2014, pp. 666.671. DOI: $10.1109 / C I C N .2014 .148$

[58] J. A. Shine, G. I. Wakefield, A comparison of supervised imagery classification using analyst-chosen and geostatistically-chosen training sets, US Army Topographic Engineering Centre, (1999), Alexandria, VA, USA. Online [Accessed 31 August 2021] http://www.geocomputation.org/1999/044/gc 044.htm

[59] ESRI, Adjust the lag size of the semivariogram model, ArcGIS 10.3- Help, Redlands, CA, USA. Online [Accessed 31 August 2021]

http://webhelp.esri.com/arcgisdesktop/9.3/tutorials/geostat/G eostat $32 . h$ tm

[60] M. Armstrong, Basic linear geostatistics, Springer Science \& Business Media (1998), ISBN: 978-3-642-58727-6.

[61] G. Bohling, Introduction to geostatistics and variogram analysis, Kansas geological survey 1 (2005), pp. 1-20. Online [Accessed 31 August 2021]

https://discoverspatial.in/wpcontent/uploads/2018/04/Variograms.pdf

[62] J. K. Yamamoto, An alternative measure of the reliability of ordinary kriging estimates, Mathematical Geology 32(4) (2000), pp. 489-509. DOI: $10.1023 / \mathrm{A}: 1007577916868$

[63] ESRI, Understanding Ordinary Kriging, ArcGIS 10.3- Help, Redlands, CA, USA. Online [Accessed 31 August 2021] http://webhelp.esri.com/arcgisdesktop/9.2/index.cfm?TopicNa $\underline{m e}=$ Understanding Ordinary Kriging

[64] M. Armstrong, Problems with universal kriging. Journal of the International Association for Mathematical Geology 16(1) (1984), pp. 101-108. DOI: $\underline{10.1007 / \mathrm{BF} 01036241}$

[65] ESRI, Understanding Universal Kriging, ArcGIS 10.3- Help, Redlands, CA, USA. Online [Accessed 31 August 2021] https://desktop.arcgis.com/en/arcmap/latest/extensions/geost atistical-analyst/understanding-universal-kriging.htm

[66] H. Wackernagel, Universal kriging, In Multivariate Geostatistics. (2003), pp. 300-307, Springer, Berlin, Heidelberg.

[67] D. Berrar, Cross-validation. Encyclopedia of bioinformatics and computational biology 1 (2019), pp. 542-545. DOI: $10.1016 /$ B978-0-12-809633-8.20349-X

[68] U. Falchi, C. Parente, G. Prezioso Global geoid adjustment on local area for GIS applications using GNSS permanent station coordinates, Geodesy and Cartography 44(3) (2018), pp. 80-88. DOI: $\underline{10.3846 / \mathrm{gac} .2018 .4356}$

[69] G. E. Fasshauer, J. G. Zhang, On choosing "optimal” shape parameters for RBF approximation, Numerical Algorithms 45(14) (2007), pp. 345-368. DOI: $10.1007 / \mathrm{s} 11075-007-9072-8$

[70] M. P. Batistella Pasini, A. Dal'Col Lúcio, A. Cargnelutti Filho, Semivariogram models for estimating fig fly population density throughout the year, Pesquisa Agropecuária Brasileira 49(7) (2014), pp. 493-505.

DOI: $10.1590 /$ S0100-204X2014000700001

[71] C. C. G. Correa, P. E. Teodoro, E. D. Cunha, J. D. Oliveira-Júnior, G. Gois, V. M. Bacani, F. E. Torres, Spatial interpolation of annual rainfall in the State Mato Grosso do Sul (Brazil) using different transitive theoretical mathematical models, International Journal of Innovative Research in Science, Engineering and Technology 3(10) (2014), pp.16618-16625. DOI: $10.15680 /$ IJIRSET.2014.0310006

[72] X. Zhang, L. Jiang, X. Qiu, J. Qiu, J. Wang, Y. Zhu, An improved method of delineating rectangular management zones using a 
semivariogram-based technique, Computers and Electronics in Agriculture 121 (2016), pp. 74-83.

DOI: $10.1016 /$ i.compag.2015.11.016

[73] I. M. Kiš, Comparison of Ordinary and Universal Kriging interpolation techniques on a depth variable (a case of linear spatial trend), case study of the Šandrovac Field, Rudarsko-geološkonaftni zbornik 31(2) (2016), pp. 41-58.

DOI: $10.17794 / \mathrm{rgn} \% 20 \mathrm{zbornik.v31i2.3862}$

[74] ESRI, Choosing a lag size, ArcGIS 10.3- Help, Redlands, CA, USA. Online [Accessed 31 August 2021]

https://desktop.arcgis.com/en/arcmap/latest/extensions/geost atistical-analyst/choosing-a-lag-size.htm
[75] W. Tobler, Measuring Spatial Resolution, Proceedings, in Land Resources Information Systems Conference, Beijing, (1987), pp. 12-16.

[76] C. Valenzuela, M. Baumgardner, Selection of appropriate cell sizes for thematic maps, ITC Journal 3 (1990), pp. 219-224.

[77] T. Hengl, Finding the right pixel size, Computers \& geosciences 32(9) (2006), pp. 1283-1298. DOI: $10.1016 /$ i.cageo.2005.11.008

[78] ESRI, Search neighborhoods, ArcGIS 10.3- Help, Redlands, CA, USA

https://desktop.arcgis.com/en/arcmap/latest/extensions/geost atistical-analyst/search-neighborhoods.htm 